\title{
The relationship between external glucose concentration and CAMP levels inside Escherichia coli: implications for models of phosphotransferase-mediated regulation of adenylate cyclase
}

\author{
Lucinda Notley-McRobb, Alison Death† and Thomas Ferenci
}

Author for correspondence: Thomas Ferenci. Tel: +6129351 4277. Fax: +61293514571. e-mail: t.ferenci@microbio.su.oz.au

Department of

Microbiology G08,

University of Sydney,

Sydney, New South Wales

2006, Australia

\begin{abstract}
The concentration of glucose in the medium influences the regulation of CAMP levels in Escherichia coli. Growth in minimal medium with micromolar glucose results in 8- to 10-fold higher intracellular cAMP concentrations than observed during growth with excess glucose. Current models would suggest that the difference in CAMP levels between glucose-rich and glucose-limited states is due to altered transport flux through the phosphoenolpyruvate: glucose phosphotransferase system (PTS), which in turn controls adenylate cyclase. A consequence of this model is that CAMP levels should be inversely related to the saturation of the PTS transporter. To test this hypothesis, the relationship between external glucose concentration and CAMP levels inside $E$. coli were investigated in detail, both through direct CAMP assay and indirectly through measurement of expression of CAMP-regulated genes. Responses were followed in batch, dialysis and glucose-limited continuous culture. A sharp rise in intracellular CAMP occurred when the nutrient concentration in minimal medium dropped to approximately $0.3 \mathrm{mM}$ glucose. Likewise, addition of $>0.3 \mathrm{mM}$ glucose, but not $<0.3 \mathrm{mM}$ glucose, sharply reduced the intracellular CAMP level of starving bacteria. There was no striking shift in growth rate or $\left[{ }^{14} \mathrm{C}\right]$ glucose assimilation in bacteria passing through the 0.5 to $0.3 \mathrm{mM}$ concentration threshold influencing CAMP levels, suggesting that neither metabolic flux nor transporter saturation influenced the sensing of nutrient levels. The (IIA/IBC) ${ }^{\text {alc }}$ PTS is $96-97 \%$ saturated at $0.3 \mathrm{mM}$ glucose so these results are not easily reconcilable with current models of CAMP regulation. Aside from the transition in CAMP levels initiated above $0.3 \mathrm{mM}$, a second shift occurred below $1 \mu \mathrm{M}$ glucose. Approaching starvation, well below saturation of the PTS, CAMP levels either increased or decreased depending on unknown factors that differ between common $E$. coli K-12 strains.
\end{abstract}

Keywords: adenylate cyclase, catabolite repression, glucose repression, continuous culture, Escherichia coli

\section{INTRODUCTION}

It is accepted that cAMP is central to the regulation of the response of Escherichia coli to different nutritional

†Present address: Department of Endocrinology, University of Sydney, NSW 2006, Australia.

Abbreviation : PTS, phosphoenolpyruvate: sugar phosphotransferase system. states (Ullmann \& Danchin, 1983; Schultz et al., 1988). Phenomena such as catabolite repression correlate with cAMP levels to some extent and growth in the presence of glucose lowers cAMP (Perlman et al., 1969). Yet there is a lack of general awareness that growth on glucose does not always result in low intracellular cAMP. Growth on low concentrations of glucose stimulates cAMP synthesis and cAMP is an important factor in bacteria adapting from glucose-excess to glucose-limited 
growth conditions. cAMP contributes to the improved scavenging ability of bacteria growing on micromolar concentrations of glucose through induction of a highaffinity transport pathway involving the binding-protein-dependent $\mathrm{Mgl}$ system and an outer-membrane glycoporin, LamB (Ferenci, 1996). These cellular components are expressed both because of endogenous inducer synthesis and because of the high level of cAMP under glucose-limited conditions.

The first study of cAMP in E. coli established that cAMP levels respond to the presence or absence of glucose in the surrounding medium (Makman \& Sutherland, 1965). However, surprisingly little information is available on what threshold level of glucose needs to be present in the environment before cAMP regulation changes. This study attempts to define the concentration of glucose in the medium leading to enhanced cAMP pools and altered gene regulation. An understanding of the nutrient concentration dependence of cAMP levels is crucial to understanding the expression of several hundred genes in E. coli controlled by the cAMP-Crp complex (Kolb et al., 1993).

The synthesis of cAMP by adenylate cyclase is thought to be the major site of regulation for controlling cAMP levels (Botsford \& Harman, 1992; Peterkofsky et al., 1993). Despite the long history of studies on the connection between glucose and cAMP synthesis, there is still an incomplete understanding of the mechanism(s) whereby adenylate cyclase recognizes the level of nutrients in the environment and reduces cAMP synthesis in their presence. The current consensus, based on work in the 1970s and 1980s, is that adenylate cyclase responds to nutrients through the functioning of sugar transporters; nutrient transport is thought to be the primary signal used to inhibit cAMP synthesis. There is evidence for this hypothesis for glucose, and models proposed by Saier (Saier \& Feucht, 1975) and Peterkofsky [Peterkofsky \& Gazdar, 1975 (reviewed by Saier, 1989; Peterkofsky et al., 1993; Postma et al., 1993)] include the involvement of the phosphoenolpyruvate:sugar phosphotransferase system (PTS) in adenylate cyclase regulation. The main elements of this model are shown in Fig. 1. The key feature is that the phosphorylation state of the glucose-specific Enzyme IIA and possibly other PTS components regulates adenylate cyclase. There is strong genetic evidence for a role of IIA and possibly Enzyme I and HPr in cAMP regulation (Levy et al., 1990; Postma et al., 1996; Saier et al., 1996). However, the in vivo regulation of adenylate cyclase has not been fully reconstituted in vitro even with the glucose phosphotransferase system and the postulated role of the level of Enzyme IIA phosphorylation in glucose inhibition of adenylate cyclase activity lacks quantitative support (Postma et al., 1992).

One previously untested consequence of transporter function in adenylate cyclase control is that the concentration-dependence of glucose transport should correlate with the concentration-dependence of adenylate cyclase regulation. Studying the effect of different external sugar concentrations on the intracellular level
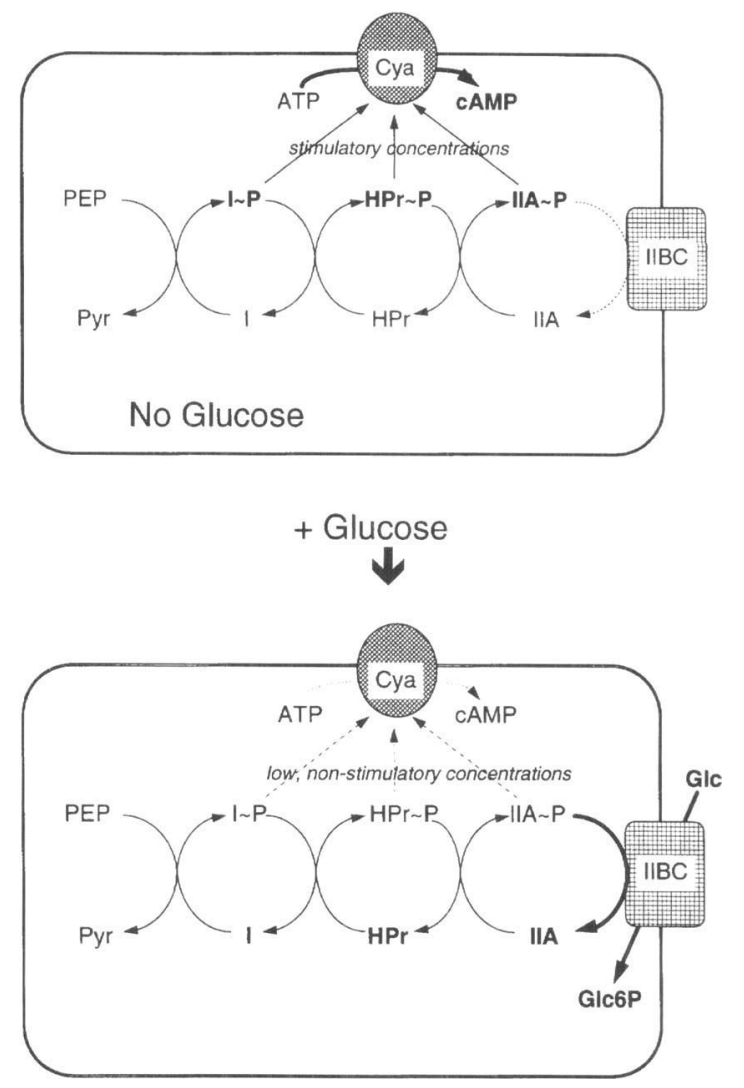

Fig. 1. A model of adenylate cyclase regulation suggesting that the phosphorylation state of glucose PTS components controls adenylate cyclase activity. In this scheme, the presence of glucose reduces the proportion of PTS components in the phosphorylated state, due to the transfer of phosphate to incoming glucose via the Enzymes IIABC. See Postma et al. (1993) for a discussion of the evidence for this model.

of cAMP should therefore help to decide whether a direct relationship exists between flux through the glucose transport system and the pool of cAMP in the cell. We present the response of cAMP levels to different medium glucose concentrations both in growing bacteria and in resting suspensions. We find that cAMP levels are upregulated in bacteria when the (IIA/IIBC) ${ }^{\text {Glc }}$ PTS transporter is still functioning close to saturation and there is little correlation between glucose flux and adenylate cyclase function.

Another unresolved area of cAMP regulation is the behaviour of $E$. coli at very low external glucose concentrations in glucose-limited continuous culture. Bacteria in glucose-limited chemostats contain elevated cAMP concentrations, but different reports give conflicting patterns of cAMP levels at different dilution rates. One report (Matin \& Matin, 1982) suggested a peak of cAMP at dilution rates around $0.5 \mathrm{~h}^{-1}$, which approximates to about $1 \mu \mathrm{M}$ glucose in the medium. In contrast, Wright et al. (1979) found almost no change in cAMP at different dilution rates. The results to be presented suggest that there is indeed a second transition affecting the intracellular concentration of cAMP at very 
low external glucose concentrations but this transition is strain dependent amongst laboratory cultures of E. coli K-12.

\section{METHODS}

Bacterial strains. All bacterial strains used in this study are derivatives of $E$. coli $\mathrm{K}-12$ and are shown in Table 1. P1 transduction (Miller, 1972) with P1 cml clr1000 grown on VH2733 and ZK1171 was used to introduce relA::Kan and rpoS: :Tn10 into BW2901 and BD21, respectively, to create BW2941 and BW2937.

Growth medium and culture conditions. The basal salts medium used in all experiments was minimal medium A (MMA) (Miller, 1972) supplemented with amino acids where necessary $\left(40 \mu \mathrm{g} \mathrm{ml}^{-1}\right)$ and glucose as specified for each experiment.

To initiate dialysis culture, approximately $5 \mathrm{ml}$ of an overnight culture of strain BW 2967 grown in MMA containing $11 \mathrm{mM}$ glucose was used to inoculate a flask containing $200 \mathrm{ml} \mathrm{MMA}$ and $10 \mathrm{mM}$ glucose. This culture was grown at $37^{\circ} \mathrm{C}$ for $3-4 \mathrm{~h}$ until the $\mathrm{OD}_{580}$ reached $0 \cdot 2-0 \cdot 3$. Then $5 \mathrm{ml}$ of this exponential culture was diluted with $45 \mathrm{ml}$ prewarmed MMA without glucose added, giving an $\mathrm{OD}_{580}$ of approximately $0.02-0.03$ and a glucose concentration of approximately $0.9 \mathrm{mM}$. Twenty millilitres of diluted culture was immediately transferred into a dialysis tube $(80 \mathrm{~cm} \times 0.8 \mathrm{~cm}$, Union Carbide Co.) which was tied at one end. The open end was secured to a metal tubing connector, through which a narrow Teflon sampling tube was inserted to the base of the dialysis tube. The Teflon sampling tube was attached to a Leuer Lock connection allowing withdrawal of sample by syringe as well as the initial injection of the culture. The entire length of dialysis tubing was immersed in a 51 medium bottle containing $41 \mathrm{MMA}$ medium with glucose at a concentration of $1 \mathrm{mM}$. The medium was kept at $37^{\circ} \mathrm{C}$ and constantly mixed with a magnetic stirrer. Two Hy-Flo air pumps sparged air into the vessel. Samples were taken to determine optical density, $\beta$ galactosidase activity and medium glucose concentration in the dialysis culture. Intracellular cAMP levels and glucose uptake rates were measured as described below.

To determine the cAMP levels in various $E$. coli strains as a function of growth rate, the chemostat conditions used in this study were as previously described (Death \& Ferenci, 1994). E. coli strains MC4100, BW2901, TP2100, BW2937 and BW2941 were grown in $80 \mathrm{ml}$ glucose-limited chemostats $(1 \cdot 1 \mathrm{mM}$ glucose input). MC4100 was also grown in an $80 \mathrm{ml}$ nitrogen-

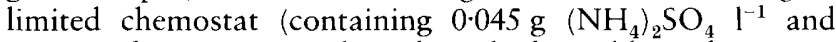
$22 \mathrm{mM}$ glucose). Once the culture had equilibrated at given dilution rates, a $5 \mathrm{ml}$ sample was removed by suction through a membrane filter to determine intracellular cAMP levels as described below.

The same continuous-culture vessels were used to determine the effect of glucose depletion on cAMP levels in E.coli strains BW2901 and MC4100. An overnight culture was used to inoculate a $570 \mathrm{ml}$ (or occasionally an $80 \mathrm{ml}$ ) culture vessel containing $1.1 \mathrm{mM}$ glucose. Bacterial growth from lag phase until final steady-state was monitored by determining $\mathrm{OD}_{580^{\circ}}$. At certain time points samples were also taken to measure residual glucose and the accumulation of intracellular and extracellular cAMP, as well as the rate of transport of $\left[{ }^{14} \mathrm{C}\right]$ glucose, $\left[{ }^{14} \mathrm{C}\right]$ maltose and $\left[{ }^{14} \mathrm{C}\right]$ galactose.

Preparation of resting cells with high cAMP content. Bacteria were grown to stationary phase in MMA supplemented with $11 \mathrm{mM}$ glucose. Approximately $12 \mathrm{~h}$ into stationary phase, bacteria were harvested after immersion in ice by centrifugation at $4{ }^{\circ} \mathrm{C}$. Aliquots were resuspended in MMA supplemented with glucose at the following concentrations: $1 \%$ $(\mathrm{w} / \mathrm{v}), 1000 \mu \mathrm{M}, 600 \mu \mathrm{M}, 400 \mu \mathrm{M}, 300 \mu \mathrm{M}, 200 \mu \mathrm{M}, 100 \mu \mathrm{M}$ and $0 \mu \mathrm{M}$. Bacteria were transferred to $37^{\circ} \mathrm{C}$, with $5 \mathrm{ml}$ samples taken to determine cAMP content after 0,2 and 10 min incubation.

$\boldsymbol{\beta}$-Galactosidase assay. The $\beta$-galactosidase activity of $\operatorname{lac} Z$ fusion strains was assayed by the method of Miller (1972).

Glucose estimation. Samples from cultures were immediately filtered as they were withdrawn through a $0 \cdot 2 \mu \mathrm{m}$ Acrodisc syringe filter (Gelman Sciences). Glucose in the filtered culture fluid was assayed using a commercial glucose oxidase method [Sigma Diagnostics Glucose (Trinder) kit].

CAMP assay. CAMP samples were taken and prepared for assay as previously described (Death \& Ferenci, 1994; Notley \& Ferenci, 1995). Samples of $5 \mathrm{ml}$ were filtered in all experiments except that $2.5 \mathrm{ml}$ of culture was filtered during the dialysis experiments. Samples were assayed using either a commercially available enzyme-linked immunoassay kit or a radioimmunoassay kit (Amersham).

Transport studies. The rate of uptake of $\left[{ }^{14} \mathrm{C}\right]$ glucose, $\left[{ }^{14} \mathrm{C}\right]$ galactose and $\left[{ }^{14} \mathrm{C}\right]$ maltose by bacteria in chemostat cultures was determined as described previously (Death $e t$ al., 1993; Notley \& Ferenci, 1995). The rate of $\left[{ }^{14} \mathrm{C}\right]$ glucose uptake by bacteria in dialysis cultures was determined by

Table 1. E. coli $\mathrm{K}-12$ derivatives used in this study

\begin{tabular}{|c|c|c|}
\hline Strain & Genotype & Origin/reference \\
\hline $\mathrm{BD} 21$ & MC4100 mglB551 $\Phi(m g l A-l a c Z)$ & Benner-Luger \& Boos (1988) \\
\hline BW2901 & HfrG6 metA & Death et al. (1993) \\
\hline BW2937 & BD21 rpos: : Tn10 & This study (parent strain VH2733) \\
\hline BW2941 & BW2901 $\Delta$ relA251:: kan & This study (parent strain ZK1171) \\
\hline BW2967 & $\begin{array}{l}\mathrm{F}^{-} \text {araD139 lacU169 malT(con) rpsL } \\
\Phi(\operatorname{lamB}-\mathrm{lac} Z)\end{array}$ & Notley \& Ferenci $(1995)$ \\
\hline MC4100 & $\begin{array}{l}\mathrm{F}^{-} \text {araD139 } \Delta(\arg F-l a c) U 169 \text { flbB5301 } \\
\text { ptsF25 rbsR deoC1 relA1 }\end{array}$ & Casabadan (1976) \\
\hline TP2100 & $\mathrm{F}^{-} x y l$ argH1 ilvA lac $\phi \phi \mathrm{X} 74$ & Roy et al. (1988) \\
\hline VH2733 & $\begin{array}{l}\text { MC4100 } \Delta \text { relA }:: \text { kan arg malB:: malE'-rrnB P1- } \\
\phi X 174 E^{\prime}-l a c Z-k a n-^{\prime} \text { malK }\end{array}$ & Hernandez \& Bremer (1991) \\
\hline ZK1171 & W3110 slacU169 tna-2 rpoS::Tn10 & Bohannon et al. (1991) \\
\hline
\end{tabular}


extracting $250 \mu \mathrm{l}$ culture sample at the same time as samples were taken to determine glucose concentration and optical density. The culture sample was immediately placed in an Eppendorf tube prewarmed at $37^{\circ} \mathrm{C}$ containing $5 \mu \mathrm{l}$ of a stock solution $(5 \mu \mathrm{M})$ of $\left[{ }^{14} \mathrm{C}\right]$ glucose $\left(302 \mathrm{mCi} \mathrm{mmol}^{-1} ; 11 \cdot 17 \mathrm{GBq}\right.$ $\left.\mathrm{mmol}^{-1}\right)$. Aliquots $(40 \mu \mathrm{l})$ were taken at 1,2,3 and $4 \mathrm{~min}$, and immediately filtered through a $0.45 \mu \mathrm{m}$ cellulose nitrate membrane filter (Whatman) and washed with $10 \mathrm{ml}$ MMA. The filters were counted in liquid scintillant (Aqueous (ounting Scintillant, Amersham) and the rate of uptake of glucose was calculated as nmol glucose transported per $10^{8}$ bacteria per minute, based on the measured glucose concentration and the optical density of the culture at the time of sampling.

\section{RESULTS}

\section{The glucose concentration threshold stimulating CAMP accumulation}

To study the transition from glucose-excess to glucoselimited growth, a culture of E. coli was inoculated at low density into a chemostat vessel containing $1.1 \mathrm{mM}$ glucose and allowed to grow under these conditions. Initially, the culture grew essentially as a batch culture without nutrient limitation. As the population built up, the glucose concentration in the vessel dropped, as shown in Fig. 2(a). But in contrast to a batch culture, the culture vessel was connected to a pump maintaining a dilution rate of $D=0.3 \mathrm{~h}^{-1}$. Hence the glucose concentration never fell to zero but the glucose-limited steady-state concentration of below $2 \mu \mathrm{M}$ was reached within $24 \mathrm{~h}$. This kind of culture prolonged the time in which the bacteria could be sampled; normal batch cultures deplete glucose too fast for frequent sampling at submillimolar concentrations of glucose in the medium, with the fall from $0.5 \mathrm{mM}$ to zero occurring in less than 30 min (Fig. 3).

As previously determined, the concentration of cAMP in steady-state glucose limited chemostats is 8 - to 10 -fold higher than in glucose-excess batch culture (Notley $\&$ Ferenci, 1995). The time-course of this transition for two E. coli strains is shown in Figs 2(a) and 2(b), which show the dramatic increase in cAMP concentrations at lower glucose concentrations. The intracellular cAMP level rises first (Figs $2 \mathrm{a}$-iii and $2 \mathrm{~b}$-ii), followed by a lag before the extracellular cAMP increases. The increase in extracellular cAMP is due to efflux (Saier et al., 1975; Matin \& Matin, 1982). The increase in cAMP efflux coincides with a decrease in intracellular levels to a new, glucose-limited steady state. This pattern suggests that efflux of cAMP builds up as a secondary event when internal levels become high. These results also suggest that the build-up of intracellular cAMP is not due to
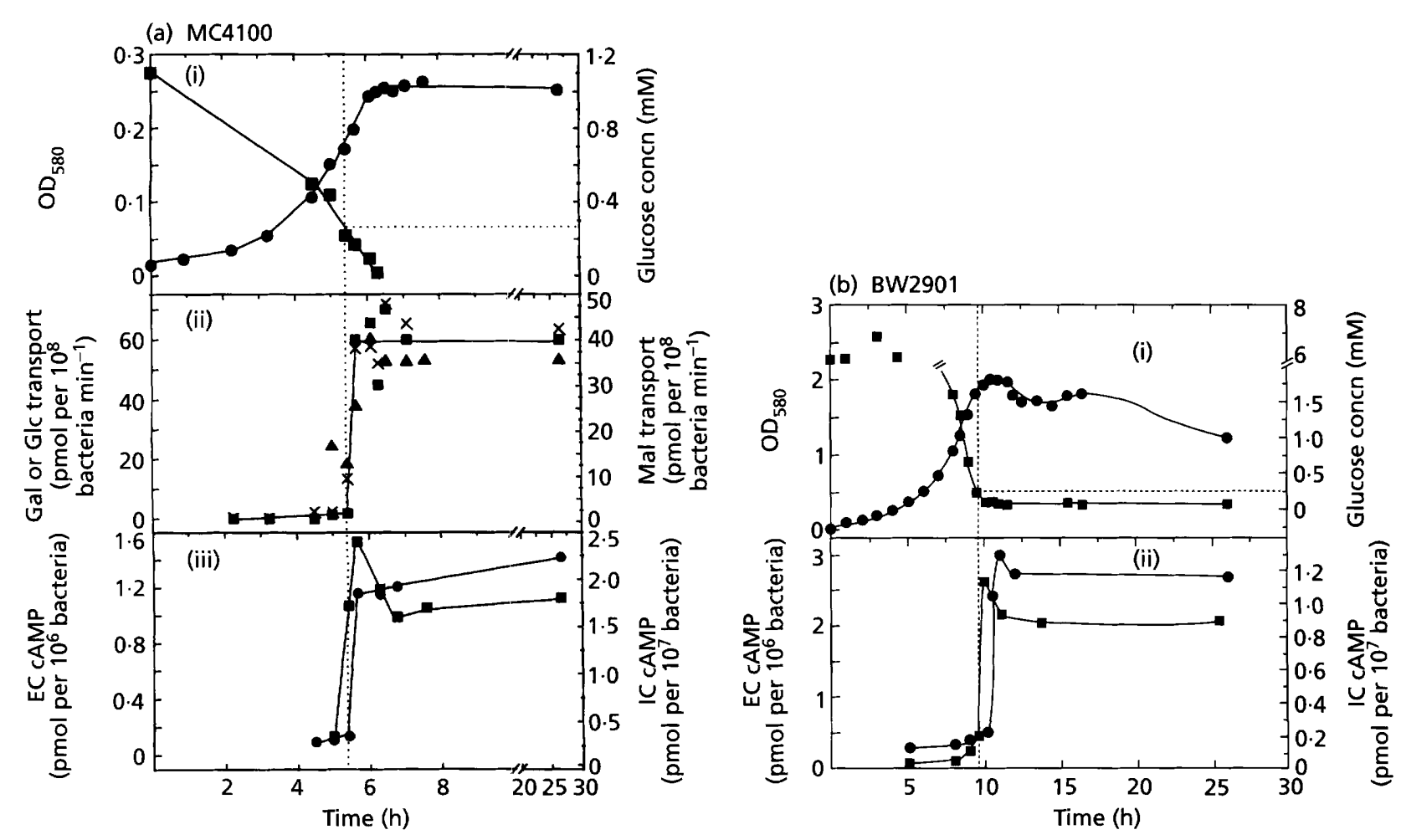

Fig. 2. Depletion of glucose by growing $E$. coli results in an increase in CAMP levels in bacteria. Strain MC4100 was used in (a) and BW2901 in (b). In both cultures, bacteria were inoculated into a chemostat vessel containing glucose-MMA medium and diluted with glucose-containing medium at a dilution rate of $0.3 \mathrm{~h}^{-1}$. Growth $\left(\mathrm{OD}_{580}\right.$, $)$ and glucose concentration ( $\mathbf{Q})$ were followed as shown in panels $(\mathrm{a}-\mathrm{i})$ and $(\mathrm{b}-\mathrm{i})$. Bacteria were sampled at given times for transport rates of glucose, maltose and galactose as shown in (a-ii). The intracellular (IC, $\boldsymbol{D}$ ) and extracellular (EC, O) CAMP levels in the culture were measured during glucose depletion as shown in (a-iii) and (b-ii). See Methods for details of the assays. 


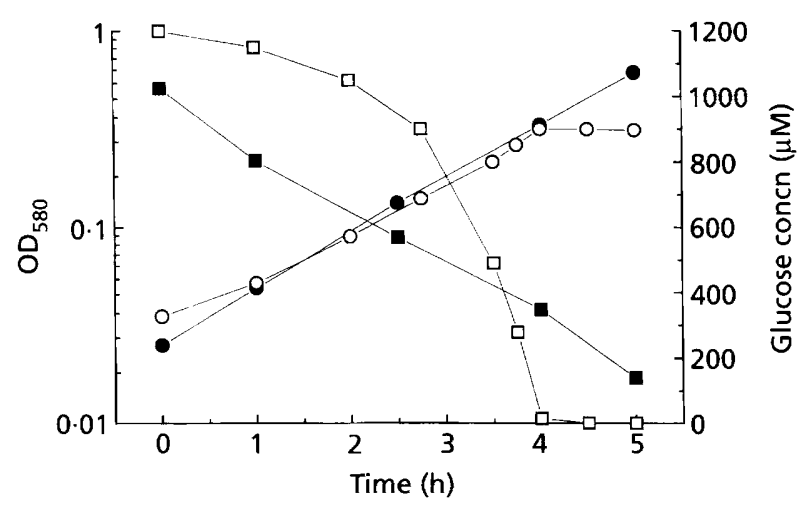

Fig. 3. A comparison of growth and glucose depletion rates in batch and dialysis culture. Batch $(\square, 0)$ and dialysis $(\boldsymbol{\square}, \boldsymbol{0})$ cultures in MMA with $1 \mathrm{mM}$ glucose were followed for strain BW2967. Glucose concentrations $(\square, \square)$ and optical density $(O$, C) were determined at the times indicated.

reduced efflux, as the total cAMP concentration in the culture (made up mainly of excreted cAMP) increased upon glucose exhaustion.

The initial increase in cAMP concentrations preceded the increase in expression of genes dependent on cAMP-Crp stimulation, such as the $m g l$ genes (Death \& Ferenci, 1994) responsible for high-affinity galactose transport, as also shown in Fig. 2(a-ii). Other cAMPCrp-regulated genes such as the mal genes responsible for maltose transport behave in a similar pattern (Fig. 2a-ii). In other experiments, transcriptional lac $Z$ fusions to $m g l$ and $m a l$ genes were found to increase in activity in the same pattern (results not shown). As expected, global gene expression responds to entry into glucose limitation following the rise in cAMP.
A surprising feature of the results shown in Fig. 2 is that the sharp increase in cAMP synthesis occurred in bacteria well before the glucose level in the medium became limiting for growth. The increase in intracellular cAMP was already well under way when residual glucose concentrations were at $0 \cdot 2-0.3 \mathrm{mM}$ in the medium, as shown by the dotted lines in Figs 2(a) and 2(b). Of course, the increase in cAMP was initiated at glucose levels above these values. Interestingly, the pattern of cAMP accumulation gives the appearance of a sudden transition event rather than a smooth increase with decreasing glucose levels. The same pattern was observed in six repeated experiments with MC4100 (and related strains such as BD21) as well as with an unrelated E. coli K-12 strain (BW2901). The latter is included in Fig. 2(b), because, as shown below, strains MC4100 and BW2901 actually differ in cAMP regulation at even lower glucose levels.

\section{CAMP transitions in dialysis culture}

The transition concentration for glucose was tested in two further approaches. Given that the concentration of glucose in the medium was rapidly dropping even in experiments such as those shown in Fig. 2, only one or two data points could be obtained for cAMP analysis at the transition point. Hence dialysis cultures were established which were growing with an even lower rate of glucose disappearance. As shown in Fig. 3, $20 \mathrm{ml}$ cultures growing in a dialysis bag with $1 \mathrm{mM}$ glucose initially present inside the bag (as well as in 4 l external bathing medium) showed exponential growth rates comparable to those of batch cultures. But dialysis resulted in a much slower reduction in glucose levels, due to the diffusion of glucose into the bags. Even when cells were growing exponentially with a doubling time of under $1 \mathrm{~h}$, the glucose concentration in dialysis
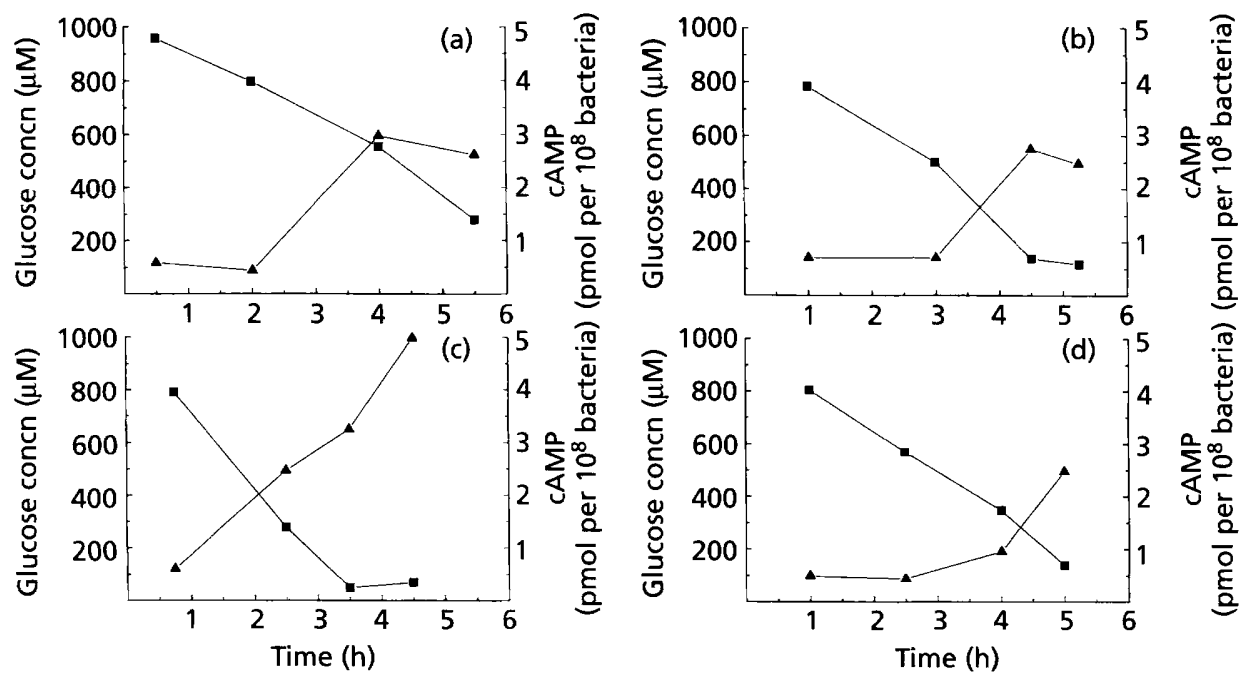

Fig. 4. Glucose depletion and CAMP levels in dialysis culture. Four independent dialysis cultures of strain BW2967 were set up with $1 \mathrm{mM}$ glucose present in the external medium. Glucose concentration ( $\boldsymbol{D}$ ) and increase in intracellular cAMP (A) were measured for each culture. 


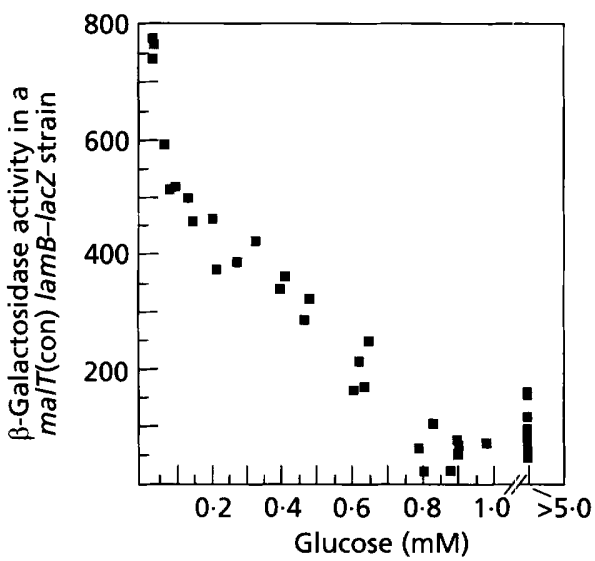

Fig. 5. CAMP-dependent gene expression in dialysis culture. The $\beta$-galactosidase activity (Miller units) of a lamB-lac transcriptional fusion in strain BW2967 was assayed in dialysis culture, starting with $1 \mathrm{mM}$ glucose in the medium. The experimental points were obtained from four independent dialysis cultures. Replicate assays were also carried out on nine batch cultures with excess glucose, containing more than $5 \mathrm{mM}$ glucose in the medium.

cultures remained in the submillimolar range for several hours.

The intracellular cAMP concentrations of bacteria in dialysis culture were measured as shown for the four independent cultures in Fig. 4. There was some variation between the residual glucose concentrations resulting in increased cAMP levels, with the cAMP increase initiated between $800-550,500-150,800-280$ and $350-150 \mu \mathrm{M}$ glucose in the medium in the experiments shown in Fig. $4(a-d)$. All these cultures were growing exponentially so it is not clear what additional factors influence the point at which cAMP levels rise. Nevertheless, it is evident that in all cultures shown in Figs 2 and 4 the residual glucose concentration was above $0.2 \mathrm{mM}$ when cAMP levels began to rise markedly. The extent of the increase was at least four- to sixfold in every culture, with the highest increase in the dialysis culture whose glucose levels continued to drop to well below $0.1 \mathrm{mM}$. The transitions in dialysis culture appeared less sharp than in the data in Fig. 2, possibly because of the extended experimental times involved in dialysis culture.

\section{CAMP-dependent gene expression at submillimolar glucose concentrations}

To provide biological evidence for increased cAMP levels, the expression of a cAMP-regulated gene was also assayed in samples taken from the dialysis culture. The gene tested was a $\operatorname{lamB} B$-lac $Z$ transcriptional fusion, in a strain in which a malT(con) mutation minimized influences other than through cAMP-Crp (Schwartz, 1987). As shown in Fig. 5, the increase in expression of cAMP-influenced expression began when the glucose concentration in the medium was approaching $0.6-0.7 \mathrm{mM}$. At concentrations close to $1 \mathrm{mM}$ glucose, the catabolite-repressed levels of cAMP and gene expression were evident. It should be noted that the increase in $\operatorname{lam} B$ gene expression was not monophasic and did not precisely follow the pattern of cAMP increases shown in Fig. 4, but the expression of mal genes is subject to other growth-related controllers besides cAMP such as Lrp (Tchetina \& Newman, 1995). Nevertheless, a marked increase in expression started below $0.7 \mathrm{mM}$ glucose and correlated with the startpoint of cAMP increases in dialysis experiments in Fig. 4.

\section{Glucose transport rates at submillimolar substrate concentrations}

All previous published data and our results with the strains used are consistent with glucose transport being half saturated around $10 \mu \mathrm{M}$ rather than in the 0.3-0.5 mM range (Death et al., 1993). But if the transport of glucose was not close to saturation at $0.3 \mathrm{mM}$ glucose, it should be evident that both growth rate and glucose metabolism should show a decrease at around the threshold level in our experiments. The data in Fig. 3 indicated no detectable decrease in growth rate between 0.5 and $0.2 \mathrm{mM}$ glucose. This was consistent with previous data determining the growth rate of $E$. coli and its dependence on nutrient concentration; growth rates on glucose are close to maximal rates until the glucose concentration is close to $10 \mu \mathrm{M}$ (Koch, 1979). Another way of testing the flux of glucose into the bacterium was to monitor the rate of glucose assimilation of a culture going through the cAMP transition of 0.7 to $0.2 \mathrm{mM}$ glucose. Bacteria actively growing on glucose were rapidly taken from dialysis culture at measured glucose concentrations and added to known amounts of $\left[{ }^{14} \mathrm{C}\right] \mathrm{glucose}$ equilibrated at $37^{\circ} \mathrm{C}$. The rate of ${ }^{14} \mathrm{C}$ uptake into filtered bacteria was measured as shown in Fig. 6. As the glucose concentration in the dialysis culture decreased in the $0.6-0.2 \mathrm{mM}$ range, there was no striking reduction in the initial glucose uptake rate, although the rate decreased with the lowest starting concentration, presumably because of glucose depletion.

The unchanged rate of glucose assimilation in the $0 \cdot 6-0 \cdot 2 \mathrm{mM}$ range was matched by the unchanged rate of glucose disappearance measured in the glucosedepleting culture in Fig. 2(a-i). Hence neither growth rate, glucose removal rate nor metabolic flux was subject to dramatic changes at external glucose concentrations in growth media leading to cAMP accumulation and induction of cAMP-Crp-dependent genes.

\section{Effect of increasing glucose concentrations on intracellular CAMP in starving bacteria}

Another independent way of testing cAMP responses to glucose was based on the experiments of Makman \& Sutherland (1965). cAMP accumulates to high levels in starving bacteria and addition of glucose chases out this accumulated cAMP. The glucose concentration-dependence of cAMP reduction was followed as shown in Fig. 


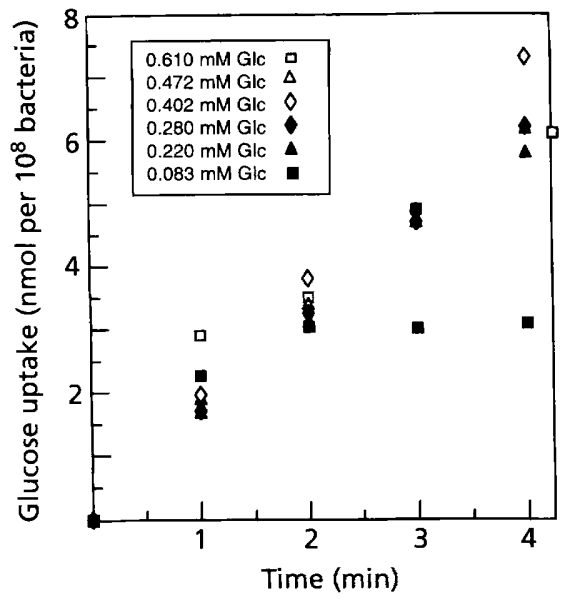

Fig. 6. Glucose assimilation rates of bacteria growing in dialysis culture. Bacteria (strain BW2967) were taken directly from a dialysis culture containing measured glucose concentrations and bacterial densities. Bacteria together with medium were immediately added to a prewarmed tube containing $\left[{ }^{14} \mathrm{C}\right]$ glucose. The glucose taken up into cells was measured by filtration of samples at the given times.

7. Using bacteria harvested in stationary phase after the exhaustion of glucose, the cAMP levels inside and outside bacteria were measured. cAMP was also measured after addition of various glucose concentrations. The striking reduction in intracellular cAMP found by Makman \& Sutherland (1965) was reproduced with addition of $1 \%$ glucose, as in their experiment. More novel was the finding that the decrease in intracellular cAMP took place with glucose concentrations down to $0.4 \mathrm{mM}$. Lower concentrations did not elicit a reduction in cAMP and, consistent with the data above, there was a clear break between the effects of 0.3 and $0.4 \mathrm{mM}$ glucose. This suggests the transitions shown in Figs 2, 4 and 5 were not simply growth-related, as suspensions also respond to the same threshold concentration of glucose in short-term experiments.

\section{A second transition in CAMP levels at very low glucose concentrations}

Glucose-limited chemostats were used to investigate the influence of very low medium concentrations on cAMP levels (Fig. 8). Residual glucose in glucose-limited chemostats is in the range micromolar to below $0 \cdot 1 \mu \mathrm{M}$, with decreasing concentrations at lower dilution rates (Senn et al., 1994). As expected from earlier studies, the cAMP concentration in bacteria growing in steadystate, glucose-limited culture was not constant when measured at different dilution rates. In strain MC4100 and its derivatives, the steady-state cAMP level increased steadily but slowly with decreasing dilution rate until a more marked transition took place at $D<0 \cdot 2 \mathrm{~h}^{-1}$ (Fig. $8 \mathrm{a})$. In these experiments the glucose concentration in the medium was close to $0 \cdot 1 \mu \mathrm{M}$ when this transition occurred. An even sharper increase at $<0 \cdot 1 \mu \mathrm{M}$ glucose

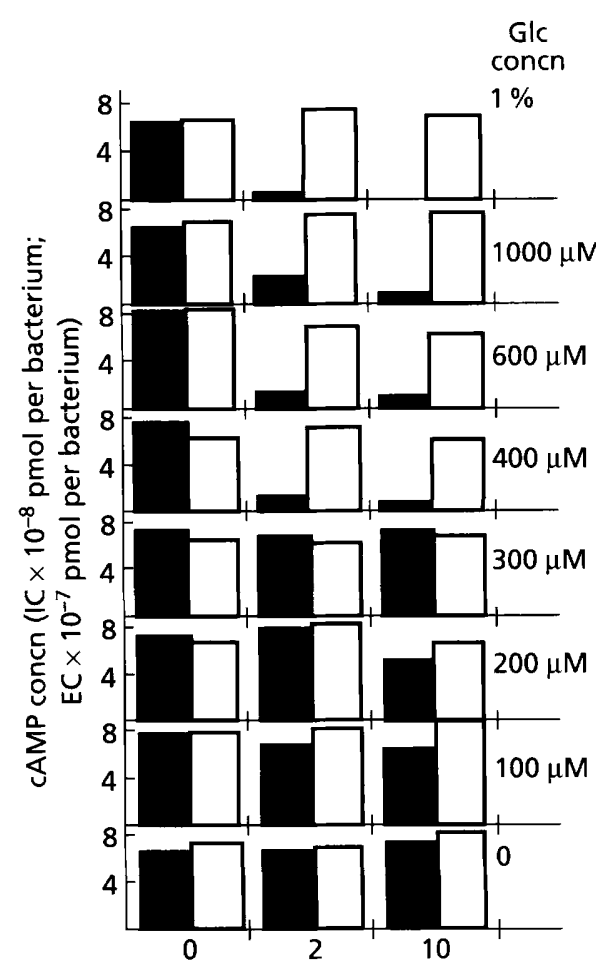

Time exposed to external glucose (min)

Fig. 7. Effect of added glucose on bacteria with high internal CAMP levels. Bacteria (MC4100) in stationary phase due to glucose depletion were harvested and resuspended in the presence of different glucose concentrations. Suspensions kept at $37^{\circ} \mathrm{C}$ were sampled to measure intracellular $(\mathbf{C})$ and extracellular ( $\square$ ) cAMP at known times.

concentrations was shown by another strain, TP2100 (Fig. 8c). Surprisingly, this trend was the opposite of that shown by another E. coli K-12 strain BW2901 (Fig. 8b). The parentage and genotypes of these strains were quite different (see Table 1). Strain BW2901 showed a far sharper increase between $D=0.9$ and $D=0.7 \mathrm{~h}^{-1}$ and also contained more cAMP at $D=0.5 \mathrm{~h}^{-1}$ than at $D=0 \cdot 1 \mathrm{~h}^{-1}$. A striking difference between strains is in the opposite responses to $<0.1 \mu \mathrm{M}$ glucose at $D<0 \cdot 2 \mathrm{~h}^{-1}$.

Earlier published studies of cAMP levels in chemostats had already provided examples of the different patterns shown in Fig. 8. Using an undescribed E. coli strain in glucose-limited chemostats, Matin \& Matin (1982) found a peak of cAMP at dilution rates around $0.5 \mathrm{~h}^{-1}$, like that of BW2901. In contrast, Wright et al. (1979) suggested a slight decrease in cAMP between $D=0.05$ and $0.4 \mathrm{~h}^{-1}$ under glucose limitation, more resembling the MC4100 pattern. Hence different E. coli K-12 strains exhibit quite different cAMP responses to decreasing growth rate due to lowered glucose concentration.

The genetic differences with respect to cAMP regulation between the strains used in Fig. 8 are as yet unknown. The most obvious possibilities were tested by constructing strains with mutations in genes known to affect 


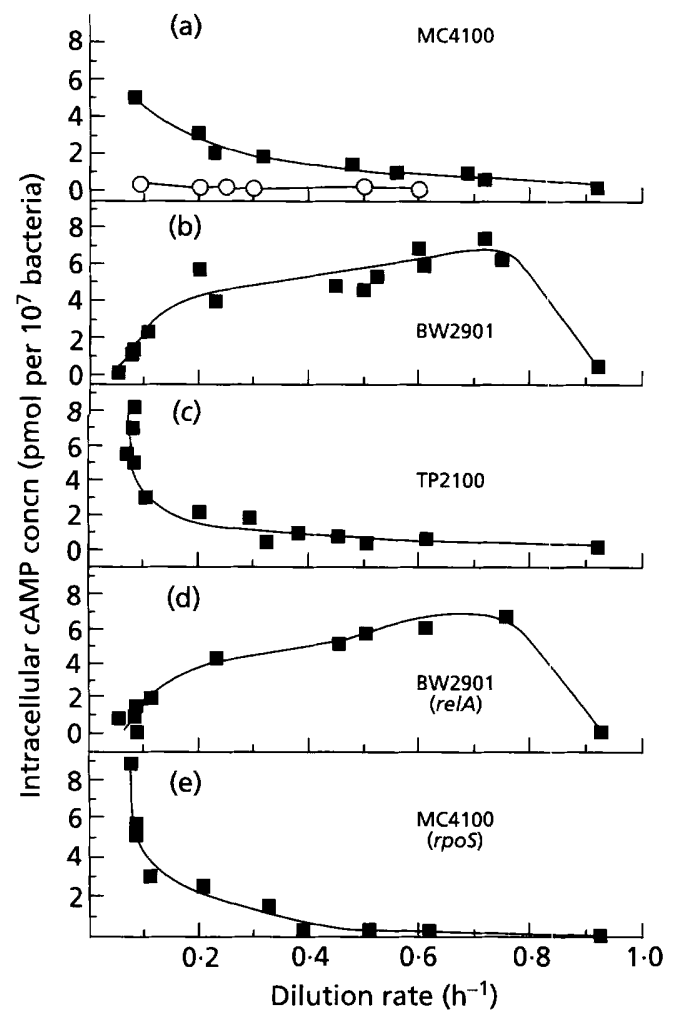

Fig. 8. Influence of dilution rate on CAMP levels in bacteria growing in glucose-limited chemostats. Bacteria supplied with limiting, $1.1 \mathrm{mM}$ glucose were sampled after equilibration at the dilution rates for all the strains indicated ( $\square$ ). For MC4100 (a), a nitrogen-limiting chemostat with excess glucose was also sampled (O).

nutrient-limited states. The pattern at low growth rate was not obviously due to $r p o S$ differences common between K-12 strains (Kaasen et al., 1992). If anything, an $r p o S$ mutation in MC4100 sharpens the increase at $D=0 \cdot 1 \mathrm{~h}^{-1}$ (Fig. 8e). The cAMP pattern of the MC4100rpoS mutant becomes more like that in TP2100, another strain used as wild-type in earlier studies (Roy et al., 1988). Testing other phenotypes (response to $\mathrm{H}_{2} \mathrm{O}_{2}$ and glycogen production) suggested that strain TP2100 is indeed an rpoS mutant. These results suggest that the known increase in RpoS activity (Notley \& Ferenci, 1996) with slow growth at low dilution rates marginally influences the cAMP levels in E. coli, but not enough to account for the major pattern differences shown in Fig. 8.

An obvious difference between strains BW2901 and MC4100 was the relA mutation present in MC4100. To test if relA affects cAMP levels at low dilution rates, the pattern in BW2901 was remeasured after the introduction of a relA mutation (Fig. $8 \mathrm{~d}$ ). There was no obvious difference between the RelA ${ }^{+}$and RelA $^{-}$strains in the BW2901 background. Hence additional differences between these strains as well as those used by Matin \& Matin (1982) or Wright et al. (1979) remain to be identified.
It should be noted that nitrogen-limited chemostats (with millimolar residual glucose) maintain a very low cAMP concentration at all dilution rates tested (Fig. 8a). The cAMP under nitrogen limitation is at glucose-excess batch-culture levels (below $3.5 \mathrm{pmol}$ per $10^{8}$ bacteria). Hence it is not solely the reduced growth rate per se that results in increased cAMP at dilution rates close to $D=0 \cdot 1 \mathrm{~h}^{-1}$ and the reduction in glucose levels is sensed in this second transition as well as above $0 \cdot 1 \mathrm{mM}$.

\section{DISCUSSION}

It is apparent from our investigation of cAMP levels at glucose concentrations ranging from millimolar to submicromolar that the level of cAMP in E. coli is not a simple function of glucose concentration in the medium. Taking into account data from batch, dialysis and chemostat cultures, E. coli controls its cAMP levels through two or more transitions influenced directly or indirectly by external glucose concentration. Our observations suggest that cAMP levels do not respond simply to decreasing saturation of glucose transport.

Most unexpectedly, cAMP levels were elevated and cAMP-Crp-controlled genes were upregulated when relatively high residual glucose concentrations $(0.3-0.5 \mathrm{mM})$ were present in the medium. Also unexpected was the pattern of the increase over a fairly narrow range of glucose concentration rather than a gradual build-up with decreasing nutrient level. These results, suggesting that control of cAMP levels is influenced by relatively high glucose concentrations, need to be considered in the context of the conventional glucose PTS mode of adenylate cyclase regulation described in Fig. 1.

The current model of glucose regulation suggests that the balance of phosphorylation of Enzyme IIA (or possibly other PTS components such as Enzyme I) governs adenylate cyclase activity, with the phosphorylated component(s) being activators. The level of phosphorylation of IIA is in turn thought to be governed by the flux towards glucose phosphorylation, with more IIA $\sim$ P being present in the absence of glucose. However, it needs to be remembered that IIA $\sim \mathrm{P}$ is never at zero concentration even with high external glucose since IIA $\sim \mathrm{P}$ is the phosphoryl donor for transport. Growth on saturating glucose must involve a steady-state concentration, $[\mathrm{IIA} \sim \mathrm{P}]_{\mathrm{n}-\mathrm{s}}$, non-stimulatory for adenylate cyclase but satisfying IIBC activity. When transport is not fully saturated, an increase in IIA concentration needs to rise to a new stimulatory value, $[\mathrm{IIA} \sim \mathrm{P}]_{\mathrm{S}}$, able to activate adenylate cyclase activity.

A threshold above $0.3 \mathrm{mM}$ is difficult to reconcile with the (IIA/IIBC) ${ }^{\mathrm{Glc}}$ PTS acting as the sensor in the above model. Glucose transport is half-saturated at $5-15 \mu \mathrm{M}$ glucose in all the cultures used in these experiments (Death \& Ferenci, 1993; Death et al., 1993; and results not shown). The cAMP transition occurs at 20-60-fold above the transport $K_{\mathrm{m}}$. The $\left[{ }^{14} \mathrm{C}\right]$ glucose uptake data and glucose removal rates during growth suggest that bacteria pass through the $0.3 \mathrm{mM}$ barrier without a 
dramatic shift in glucose transport rates. Assuming a simple Michaelis-Menten relationship and a $K_{\mathrm{m}}$ of $10 \mu \mathrm{M}$ for glucose transport (Death et al., 1993), it can be calculated that the PTS is operating at $96.8 \%$ saturation instead of $97.6 \%$ in dropping from 0.4 to $0.3 \mathrm{mM}$ medium glucose. There is no information as to how such a small decrease in flux translates to changes in IIA phosphorylation from the non-stimulatory $\left([\mathrm{IIA} \sim \mathrm{P}]_{\mathrm{n}-\mathrm{s}}\right)$ to the stimulatory $\left([\mathrm{IIA} \sim \mathrm{P}]_{\mathrm{S}}\right)$. It is difficult to envisage mechanistically how adenylate cyclase could be totally poised to sense the shift in $[\text { IIA } \sim \mathrm{P}]_{\mathrm{n}-\mathrm{s}}$ to $[\mathrm{IIA} \sim \mathrm{P}]_{\mathrm{s}}$ resulting from minor changes in saturation with glucose. Perhaps if one postulates an exceptionally sigmoidal response of adenylate cyclase to IIA $\sim P$, then the data we present can be considered within the IIA $\sim \mathrm{P}$ model of adenylate cyclase regulation. The in vitro data with adenylate cyclase and its stimulation by IIA $\sim \mathrm{P}$ do not provide much evidence to support this and, on balance, this mechanism does not satisfactorily explain the stimulation of cAMP synthesis at 0.5 to $0.3 \mathrm{mM}$ glucose. Likewise, other models based on adenylate cyclase regulation by components of the PTS such as enzyme $\mathrm{I} / \mathrm{I} \sim \mathrm{P}$ ratios fail to explain the phenomenon described in this study for similar reasons as considered for IIA.

The above considerations do not refute the great deal of genetic evidence that PTS components are important for adenylate cyclase activity. There is no doubt that the PTS is significant in adenylate cyclase regulation, but the difficulty is in adopting the view that the phosphorylation state of components like IIA is the means of sensing glucose in the medium. An alternative explanation of the role of IIA/IIA $\sim \mathrm{P}$ is that phosphorylated PTS components are required to bring adenylate cyclase into an activatable form in conjunction with other inputs. In this scenario, $\mathrm{I} \sim \mathrm{P}$ or IIA $\sim \mathrm{P}$ are essential for adenylate cyclase activity but the major stimulation of cAMP synthesis is due to other sensory inputs.

Effectors of adenylate cyclase besides the PTS are already recognized. Biochemical approaches suggest that a number of effectors influence adenylate cyclase (Peterkofsky et al., 1993) but none are obviously controlled by glucose concentrations in the medium. It is also known that non-PTS sugars like gluconate or glucose 6phosphate strongly influence cAMP levels (Epstein et al., 1975; Joseph et al., 1982) and adenylate cyclase inputs other than IIA $\sim$ P need to be postulated for non-glucose sugars as well (Dumay et al., 1996).

At this stage, there is no simple model available to explain the transition phenomenon at submillimolar glucose concentrations. More speculative explanations can be offered, such as the operation of a receptor system recognizing glucose with an affinity in the submillimolar range and signalling to adenylate cyclase directly. A possible candidate with corresponding affinities is the Enzyme II $^{\mathrm{Man}}$ system, which recognizes glucose with millimolar $K_{\mathrm{m}}$ (Hunter \& Kornberg, 1979). However, there is no genetic or biochemical evidence to suggest the II ${ }^{\text {Man }}$ system is involved in adenylate cyclase regulation. Evidence for alternative receptor(s) is lacking. Clearly, there is a great need for experimental work on adenylate cyclase regulation before we understand how a key central regulator like cAMP is itself controlled.

Our dire lack of information on cAMP regulation was also highlighted by the pattern differences shown in Fig. 8 at limiting (submicromolar) glucose concentrations. There are additional input(s) into controlling cAMP levels operating at very low nutrient levels of which we are totally ignorant. So much for the best-understood organism!

\section{ACKNOWLEDGEMENTS}

We thank the sources of the bacterial strains listed in Table 1, and the Australian Research Council for grant support.

\section{REFERENCES}

Benner-Luger, D. \& Boos, W. (1988). The $m g l B$ sequence of Salmonella typhimurium LT2; promoter analysis by gene fusions and evidence for a divergently oriented gene coding for the $\mathrm{mgl}$ repressor. Mol Gen Genet 214, 579-587.

Bohannon, D. E., Connell, N., Keener, J., Tormo, A., EspinosaUrgel, M., Zambrano, M. M. \& Kolter, R. (1991). Stationary-phaseinducible 'gearbox' promoters: differential effects of katF mutations and role of sigma 70.J Bacteriol 173, 4482-4492.

Botsford, J. L. \& Harman, J. G. (1992). Cyclic AMP in prokaryotes. Microbiol Rev 56, 100-122.

Casabadan, M. J. (1976). Transposition and fusion of the lac operon to selected promoters in $E$. coli using bacteriophage Lambda and Mu. J Mol Biol 104, 541-555.

Death, A. \& Ferenci, T. (1993). The importance of the bindingprotein-dependent $\mathrm{Mgl}$ system to the transport of glucose in Escherichia coli growing on low sugar concentrations. Res Microbiol 144, 529-537.

Death, A. \& Ferenci, T. (1994). Between feast and famine: endogenous inducer synthesis in the adaptation of Escherichia coli to growth with limiting carbohydrates. J Bacteriol 176, 5101-5107.

Death, A., Notley, L. \& Ferenci, T. (1993). Derepression of LamB protein facilitates outer membrane permeation of carbohydrates into Escherichia coli under conditions of nutrient stress. J Bacteriol 175, 1475-1483.

Dumay, V., Danchin, A. \& Crasnier, M. (1996). Regulation of Escherichia coli adenylate cyclase activity during hexose phosphate transport. Microbiology 142, 575-583.

Epstein, W., Rothman-Denes, L. B. \& Hesse, J. (1975). Adenosine $3^{\prime}: 5^{\prime}$-cyclic monophosphate as mediator of catabolite repression in Escherichia coli. Proc Natl Acad Sci USA 72, 2300-2304.

Ferenci, T. (1996). Adaptation to life at micromolar nutrient levels: the regulation of Escherichia coli glucose transport by endoinduction and cAMP. FEMS Microbiol Rev 18, 301-317.

Hernandez, V. J. \& Bremer, H. (1991). E. coli ppGpp synthetase II activity requires spoT. J Biol Chem 266, 5991-5999.

Hunter, I. S. \& Kornberg, H. L. (1979). Glucose transport of Escherichia coli growing in glucose-limited continuous culture. Biochem J 178, 97-101. 
Joseph, E., Bernsley, C., Guiso, N. \& Ullmann, A. (1982). Multiple regulation of the activity of adenylate cyclase in Escherichia coli. Mol Gen Genet 185, 262-268.

Kaasen, I., Falkenberg, P., Styrvold, O. B. \& Strom, A. R. (1992). Molecular cloning and physical mapping of the otsBA genes, which encode the osmoregulatory trehalose pathway of Escherichia coli: evidence that transcription is activated by katF (appR). J Bacteriol 174, 889-898.

Koch, A. L. (1979). Microbial growth in low concentrations of nutrients. In Strategies of Microbial Life in Extreme Environments, pp. 261-279. Edited by M. Shilo. Weinheim: Verlag Chemie.

Kolb, A., Busby, S., Buc, H., Garges, S. \& Adhya, S. (1993). Transcriptional regulation by cAMP and its receptor protein. Annu Rev Biochem 62, 749-795.

Levy, S., Zeng, G. Q. \& Danchin, A. (1990). Cyclic AMP synthesis in Escherichia coli strains bearing known deletions in the pts phosphotransferase operon. Gene 86, 27-33.

Makman, R. S. \& Sutherland, E. W. (1965). Adenosine $3^{\prime}, 5^{\prime}$ phosphate in Escherichia coli. J Biol Chem 240, 11309-1314.

Matin, A. \& Matin, M. K. (1982). Cellular levels, excretion and synthesis rates of cAMP in Escherichia coli grown in continuous culture. J Bacteriol 149, 801-817.

Miller, J. (1972). Experiments in Molecular Genetics. Cold Spring Harbor, NY: Cold Spring Harbor Laboratory.

Notley, L. \& Ferenci, T. (1995). Differential expression of mal genes under CAMP and endogenous inducer control in nutrient stressed Escherichia coli. Mol Microbiol 16, 121-129.

Notley, L. \& Ferenci, T. (1996). Induction of RpoS-dependent functions in glucose-limited continuous culture: what level of nutrient limitation induces the stationary phase of Escherichia coli? J Bacteriol 178, 1465-1468.

Perlman, R. L., De Crombrugghe, B. \& Pastan, I. (1969). Cyclic AMP regulates catabolite and transient repression in $E$. coli. Nature 223, 810-812.

Peterkofsky, A. \& Gazdar, C. (1975). Interaction of enzyme I of the phosphoenolpyruvate:sugar phosphotransferase system with adenylate cyclase of Escherichia coli. Proc Natl Acad Sci USA 72, 2920-2924.

Peterkofsky, A., Reizer, A., Reizer, J., Gollop, N., Zhu, P. P. \& Amin, N. (1993). Bacterial adenylyl cyclases. Prog Nucleic Acid Res Mol Biol 44, 31-65.

Postma, P. W., Ruijter, G. J. G., van der Vlag, J. \& van Dam, K. (1992). Control of carbohydrate metabolism in enteric bacteria: qualitative and quantitative aspects. In Molecular Mechanisms of Transport, pp. 97-105. Edited by E. Quagliarello \& F. Palmieri. Amsterdam : Elsevier.

Postma, P. W., Lengeler, J. W. \& Jacobson, G. R. (1993). Phosphoenolpyruvate: carbohydrate phosphotransferase systems of bacteria. Microbiol Rev 57, 543-594.
Postma, P., Lengeler, J. W. \& Jacobson, G. R. (1996). Phosphoenolpyruvate:carbohydrate phosphotransferase systems. In Escherichia coli and Salmonella: Cellular and Molecular Biology, 2nd edn, pp. 1149-1174. Edited by F. C. Neidhardt and others. Washington, DC: American Society for Microbiology.

Roy, A., Glaser, P. \& Danchin, A. (1988). Aspects of the regulation of adenylate cyclase synthesis in Escherichia coli K12. $J$ Gen Microbiol 134, 359-367.

Saier, M. H., Jr (1989). Protein phosphorylation and allosteric control of inducer exclusion and catabolite repression by the bacterial phosphoenolpyruvate:sugar phosphotransferase system. Microbiol Rev 53, 109-120.

Saier, M. H., Jr \& Feucht, B. U. (1975). Coordinate regulation of adenylate cyclase and carbohydrate permeases by the phosphoenolpyruvate:sugar phosphotransferase system in Salmonella typhimurium. J Biol Chem 250, 7078-7080.

Saier, M. H., Jr, Feucht, B. U. \& McCaman, M. T. (1975). Regulation of intracellular adenosine cyclic $3^{\prime}: 5^{\prime}$-monophosphate levels in Escherichia coli and Salmonella typhimurium. Evidence for energy-dependent excretion of the cyclic nucleotide. J Biol Chem 250, 7593-7601.

Saier, M. H., Jr, Ramseier, T. M. \& Reizer, J. (1996). Regulation of carbon utilisation. In Escherichia coli and Salmonella: Cellular and Molecular Biology, 2nd edn, pp. 1325-1343. Edited by F. C. Neidhardt and others. Washington, DC: American Society for Microbiology.

Schultz, J. E., Latter, G. I. \& Matin, A. (1988). Differential regulation by cyclic AMP of starvation protein synthesis in Escherichia coli. J Bacteriol 170, 3903-3909.

Schwartz, M. (1987). The maltose regulon. In Escherichia coli and Salmonella: Cellular and Molecular Biology, pp. 1482-1502. Edited by F.C. Neidhardt and others. Washington, DC: American Society for Microbiology.

Senn, H., Lendenmann, U., Snozzi, M., Hamer, G. \& Egli, T. (1994). The growth of Escherichia coli in glucose-limited chemostat cultures: a re-examination of the kinetics. Biochim Biophys Acta $1201,424-436$

Tchetina, E. \& Newman, E. B. (1995). Identification of lrpregulated genes by inverse PCR and sequencing - regulation of two mal operons of Escherichia coli by leucine-responsive regulatory protein. J Bacteriol 177, 2679-2683.

Ullmann, A. \& Danchin, A. (1983). Role of cyclic AMP in bacteria. Adv Cyclic Nucleotide Res 15, 1-53.

Wright, L. F., Milne, D. \& Knowles, C. J. (1979). The regulatory effects of growth rate and cAMP levels on carbon catabolism and respiration in Escherichia coli K-12. Biochim Biophys Acta 539, 73-80.

Received 10 September 1996; revised 19 December 1996; accepted 20 January 1997. 